\title{
IMPACTOS NA ARRECADAÇÃO DE ROYALTIES DE PETRÓLEO PROVOCADOS PELO EFEITO CORONAVÍRUS NO PRIMEIRO SEMESTRE DE 2020
}

\author{
IMPACTS ON OIL ROYALTY COLLECTION CAUSED BY THE CORONAVIRUS EFFECT IN THE FIRST \\ HALF OF 2020
}

Resumo: A crise gerada pela COVID-19 impactou elementos essenciais no cálculo das participações governamentais no Brasil, especialmente na cotação do petróleo tipo Brent, cotação internacional do gás e na queda de demanda, com reflexos diretos na produção. Neste trabalho, são abordados os impactos financeiros decorrentes da perda de receita de royalties e participação especial no primeiro semestre de 2020, avaliando individualmente os efeitos dos parâmetros de cálculo das respectivas participações governamentais. No período, houve um impacto significativo nas receitas geradas por royalties e participação especial provenientes da indústria do petróleo e gás, chegando a superar uma perda de $60 \%$ no período mais crítico de produção.

Palavras-chave: Royalties de petróleo. COVID-19. Participações governamentais.
Abstract: The crisis generated by COVID-19 has impacted essential elements in the calculation of government participation in Brazil, especially the Brent oil price, the international gas price, and the fall in demand, with direct repercussion on production. This work addresses the financial impacts resulting from the loss of royalty revenue and special participation in the first half of 2020, evaluating individually the effects of the parameters for calculating the respective government participation. In the period, there was a significant impact on revenue generated by royalties and special participation from the oil and gas industry, reaching a loss of $60 \%$ in the most critical period of production.

Keywords: Oil Royalties. COVID-19. Government Participations.

João Paulo Lima Santos

Doutor em Engenharia Civil pela COPPE/UFRJ. Universidade Federal de Alagoas, Centro de Tecnologia, Campus A.C Simões, Tabuleiro do Martins, Maceió (AL), Brasil. CEP: 57072-970. Telefone (82) 3214-1303. E-mail: jpls@lccv.ufal.br

\section{Gabriel Marcuzzo do Canto Cavalheiro}

Doutor em Administração pela Fundação Getúlio Vargas (FGV). Universidade Federal Fluminense, Centro de Estudos Sociais Aplicados, Faculdade de Administração e Ciências Contábeis. 


\section{INTRODUÇÃO}

Segundo a Constituição brasileira, é assegurada, nos termos da lei, aos estados, ao Distrito Federal e aos municípios bem como a órgãos da administração direta da União a participação no resultado da exploração de petróleo ou gás natural, de recursos hídricos para fins de geração de energia elétrica e de outros recursos minerais no respectivo território, plataforma continental, mar territorial ou zona econômica exclusiva, ou compensação financeira por essa exploração (Constituição Federal de1988).

No Brasil, o petróleo pertence à União, embora a Lei n. . 9.478/1997 garanta que, após extraído, passe a ser da empresa que realiza a extração deste recurso natural mediante o pagamento dos royalties relativos ao produto. A remuneração é dada ao estado/ sociedade pela exploração desses recursos não renováveis. Os royalties e Participação Especial (PE) são participações governamentais oriundas da exploração e produção de petróleo e gás natural, conforme previsto na Lei n. ${ }^{0} 9.478$, de 6 de agosto de 1997.

Os royalties incidem sobre o valor da produção do campo e são recolhidos mensalmente pelas empresas concessionárias por meio de pagamentos efetuados à Secretaria do Tesouro Nacional (STN) até o último dia do mês seguinte àquele em que ocorreu a produção. A STN repassa os royalties aos beneficiários com base nos cálculos efetuados pela Agência Nacional do Petróleo, Gás e Biocombustíveis (ANP), de acordo com o estabelecido pelas Leis n. ${ }^{0}$ 9.478/1997 e n. ${ }^{0}$ 7.990/1989, regulamentadas, respectivamente, pelos decretos n. ${ }^{0}$ 2.705/1998 e n.0 1/1991. A PE é aplicada sobre a receita bruta da produção deduzidos os royalties, os investimentos na exploração, os custos operacionais, a depreciação e os tributos previstos na legislação em vigor. Os procedimentos para a apuração da PE são definidos por meio da Resolução ANP n. ${ }^{0}$ 12, de 21/02/2014, em complementação ao Decreto n. ${ }^{0} 2.705 / 98$, sendo calculados trimestralmente.

Segundo Badiani (2019), a dependência das receitas municipais em relação aos repasses dos royalties merece especial atenção dos executivos, considerando as incertezas do processo de E\&P do petróleo. Essas incertezas estão associadas diretamente à perda de receita consequente da cotação internacional do petróleo bem como de impactos oriundos de redução de produção.

A crise gerada pela COVID-19 impactou elementos essenciais no cálculo das participações governamentais no Brasil, especialmente: i) a cotação do petróleo tipo Brent (comercializado na bolsa de Londres em dólar) e cotação internacional do gás; ii) a queda de demanda, com reflexos diretos na produção; eiii) os impactos cambiais de variação de dólar no período.

Neste trabalho, são abordados os impactos financeiros decorrentes da perda de receita de royalties e participação especial no primeiro semestre de 2020 para as entidades nacionais, avaliando, individualmente, os efeitos dos parâmetros de cálculo das respectivas participações governamentais.

\section{METODOLOGIA DE CÁLCULO DE ROYALTIES E PARTICIPAÇÃO ESPECIAL}

No Brasil, o cálculo das participações governamentais do tipo royalties e participação especial é realizado com base na média mensal do preço do petróleo tipo Brent e da cotação internacional do gás, incorporando no cálculo um diferencial de qualidade, ajustado com base no perfil de produção de cada campo produtor. Para cálculo oficial, a ANP procede mensalmente o cálculo do Preço de Referência do Petróleo (Ppetr) e Gás (PGas) em cada campo produtor, estabelecendo 0 valor de produção Vp com base nos volumes produzidos de petróleo Vpetr e gás VGas em cada campo produtor, conforme a Eq. 1.

$$
V_{p}=V_{\text {petrPpetr }} V_{\text {GasP }} \text { Gas }
$$

0 preço de referência Ppetr do petróleo nacional (segundo Decreto n.0 9.042/2017) é calculado para cada mês, em reais por metro cúbico, sendo obtido pela média mensal do preço do petróleo tipo Brent, em dólares por barril, ao qual se incorpora um diferencial de qualidade (positivo ou negativo) visando adequar o preço da corrente avaliada à sua qualidade. A conversão para a moeda nacional é feita pela média mensal das taxas de câmbio diárias de compra do dólar norte-americano, segundo informado pelo Banco Central do Brasil, conforme a Eq. 2, sendo Pref o preço de referência do petróleo da corrente em $\mathrm{R} \$ / \mathrm{m}^{3}$; TC, a média mensal das taxas de câmbio diárias para compra do dólar americano; e $D Q$, o diferencial de qualidade entre o petróleo produzido no campo e o petróleo de referência (Brent).

$$
\text { Ppetr=TC.6,2898.(PreftDQ) }
$$

Ainda existem algumas particularidades em relação ao cálculo Ppetr, quando, por exemplo, o petróleo produzido não dispuser de curva PEV (Ponto de Ebulição Verdadeiro) bem como em situações em que ocorre a primeira área produtora de sua bacia, conforme pode ser detalhado na Resolução ANP n. ${ }^{\circ}$ 703/2017.

A Resolução ANP n. ${ }^{\circ}$ 40, de 14 de dezembro de 2009, estabelece os critérios para fixação do preço de referência do gás natural (PRGN) produzido nos campos objeto de concessão pela ANP. A metodologia de cálculo do PRGN para cada campo produtor utiliza como referência a média mensal das cotações 
internacionais diárias dos preços de quatro frações possíveis de serem extraídas do gás natural.

0 PGas, em reais por metro cúbico, é obtido pelo somatório dos produtos das frações volumétricas do gás natural que, após seu processamento, podem ser obtidas (condensado de gás natural, gás liquefeito de petróleo e gás processado) pelos correspondentes preços. A conversão para a moeda nacional é feita pela média mensal das taxas de câmbio diárias de compra do dólar norte-americano, segundo o Banco Central do Brasil (Resolução ANP n. ${ }^{0}$ 40/2009).

A alíquota para o cálculo dos royalties do campo produtor pode variar de 5\% a 15\%, dependendo do contrato. Para cálculo da participação especial, levam-se em consideração alíquotas progressivas que dependem da localização do campo de produção, do número de anos de produção e do volume de produção trimestral.

\section{RESULTADOS E DISCUSSÕES}

0 preço da produção do petróleo Ppetr depende, em essência, da cotação do preço do petróleo tipo Brent. Na abertura do semestre 2020.1, o Brent foi comercializado a US\$ 66,25/barril. Devido às incertezas trazidas pela COVID-19 somadas a fatores geopolíticos entre países produtores, atingiu-se um valor mínimo de fechamento de US\$ 19,33 de 21/04/2020, acarretando uma queda de 70,82\% em relação ao início do semestre. No decorrer do semestre, houve recuperação de preço, atingindo o preço de fechamento de US\$ 41,15/barril em 30/06/2020, conforme pode ser observado na Fig. 1, registrando ainda uma queda de preço de 37,88\% em relação ao início do semestre 2020.1 .

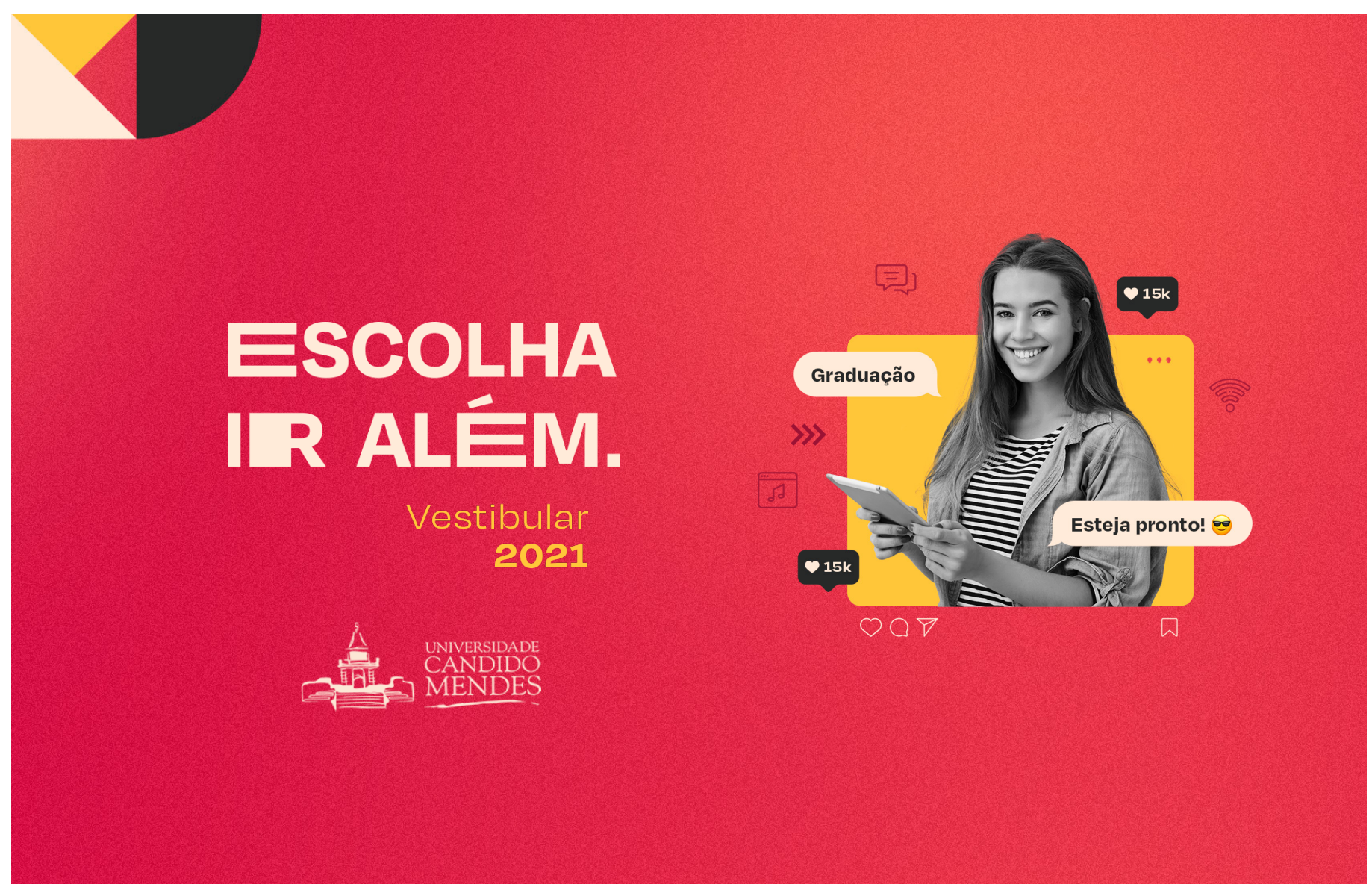


Figura 1: Histórico de preços do petróleo tipo Brent no primeiro semestre

de 2020

\section{Cotação do Brent (U\$)}

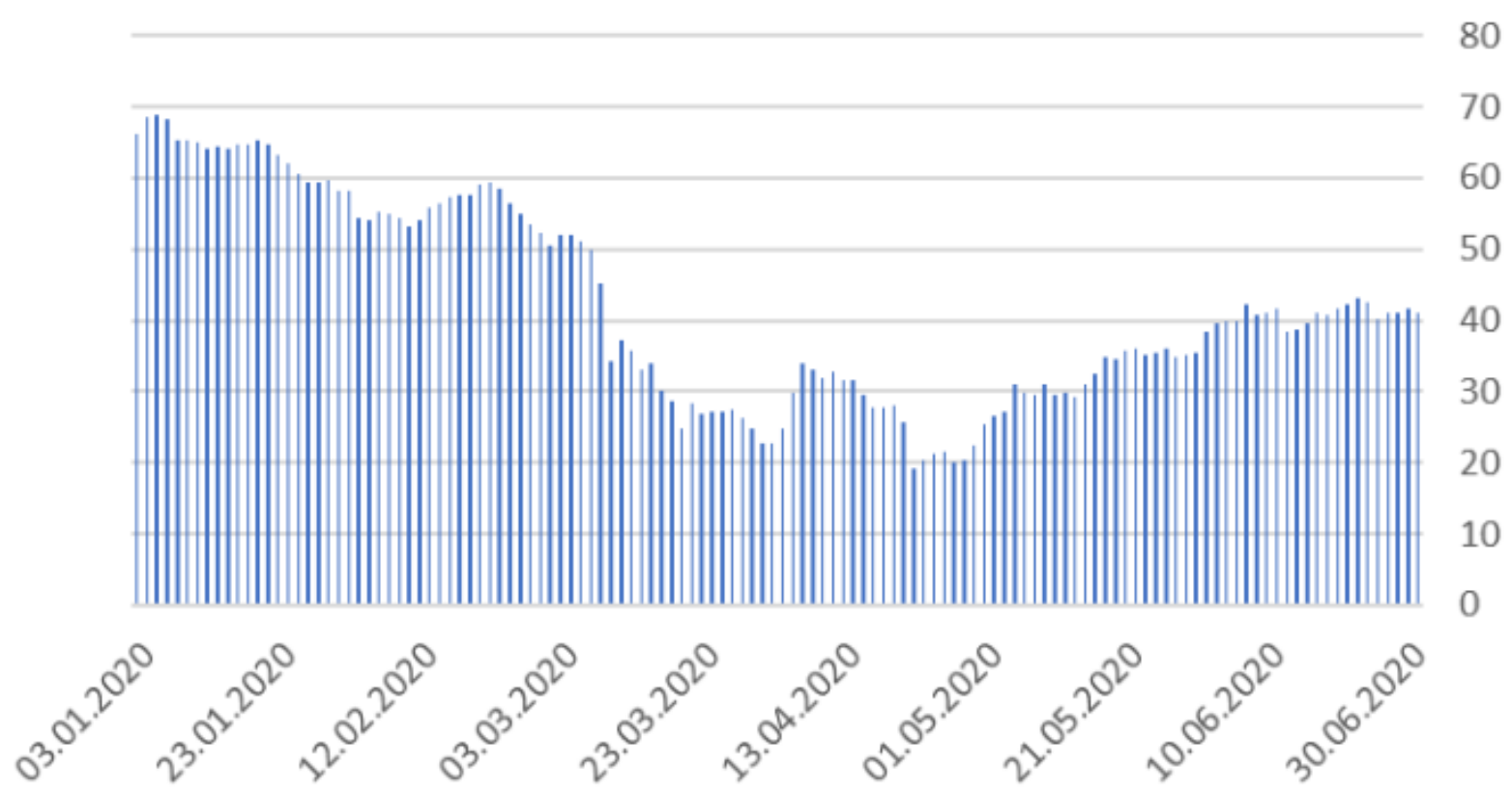

FONTE: Autor (2020), com base em dados de histórico de cotação

Os volumes de produção de petróleo Vpetr e gás VGas sofreram grande impacto no período, sobretudo induzido pela queda de demanda de consumo nacional e internacional frente às medidas de distanciamento social impostas no combate à COVID-19. 0 levantamento de dados de produção (Fig. 2) aponta que o mês de maio apresentou maior impacto na produção de petróleo, com redução de 13\% em relação ao mês de janeiro de 2020. 0 encerramento do semestre apresenta recuperação, porém ainda com um volume de produção, em junho, 8\% menor em relação ao de janeiro (início do semestre). 0 volume de produção de gás VGas chegou a recuar 29,6\% no mês de abril, encerrando o semestre com queda de 20\% em relação a janeiro de 2020, conforme Fig. 3. 
Figura 2: Histórico de produção de petróleo no Brasil - primeiro semestre de 2020/2019

\section{Produção de petróleo total (bep)}

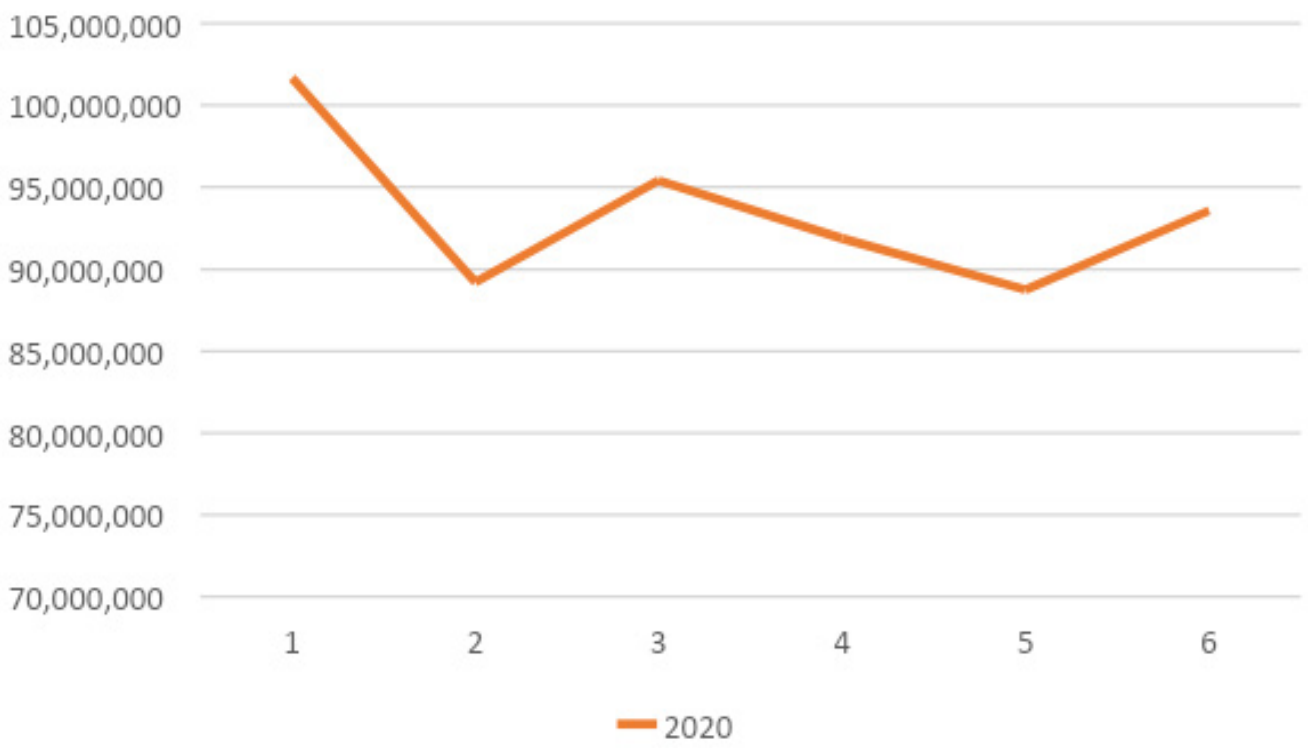

FONTE: Autor (2020), com base em dados da ANP

Figura 3: Histórico de produção de gás no Brasil - primeiro semestre de 2020/2019

Gás natural disponível (beq)

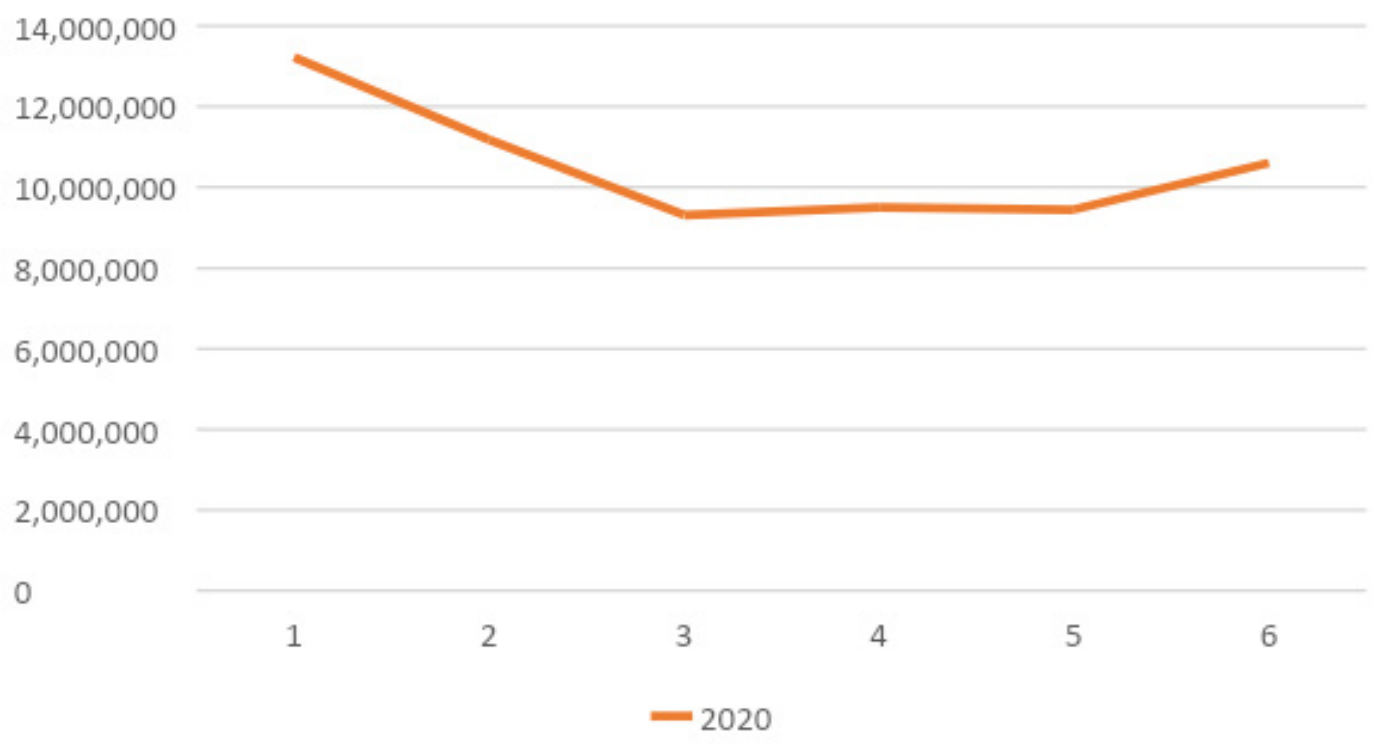

FONTE: Autor (2020), com base em dados da ANP 
Devido ao grande impacto na cotação do Brent e na demanda de venda no período, as operadoras que atuam no Brasil adotaram uma série de medidas de resiliência, reduzindo, por exemplo, a produção em campos com maior custo de operação. A participação de produção em terra, que foi de 6,63\% em janeiro, caiu para 5,5\% em abril, conforme perfil de produção apresentado na Fig. 4. Tais alterações também afetam a receita total de royalties e participação especial, em função da influência da qualidade de óleo produzido no cálculo do preço mínimo do petróleo, que é calculado para o perfil de cada campo produtor no período.

Figura 4: Perfil de produção de petróleo no Brasil - primeiro semestre de 2020

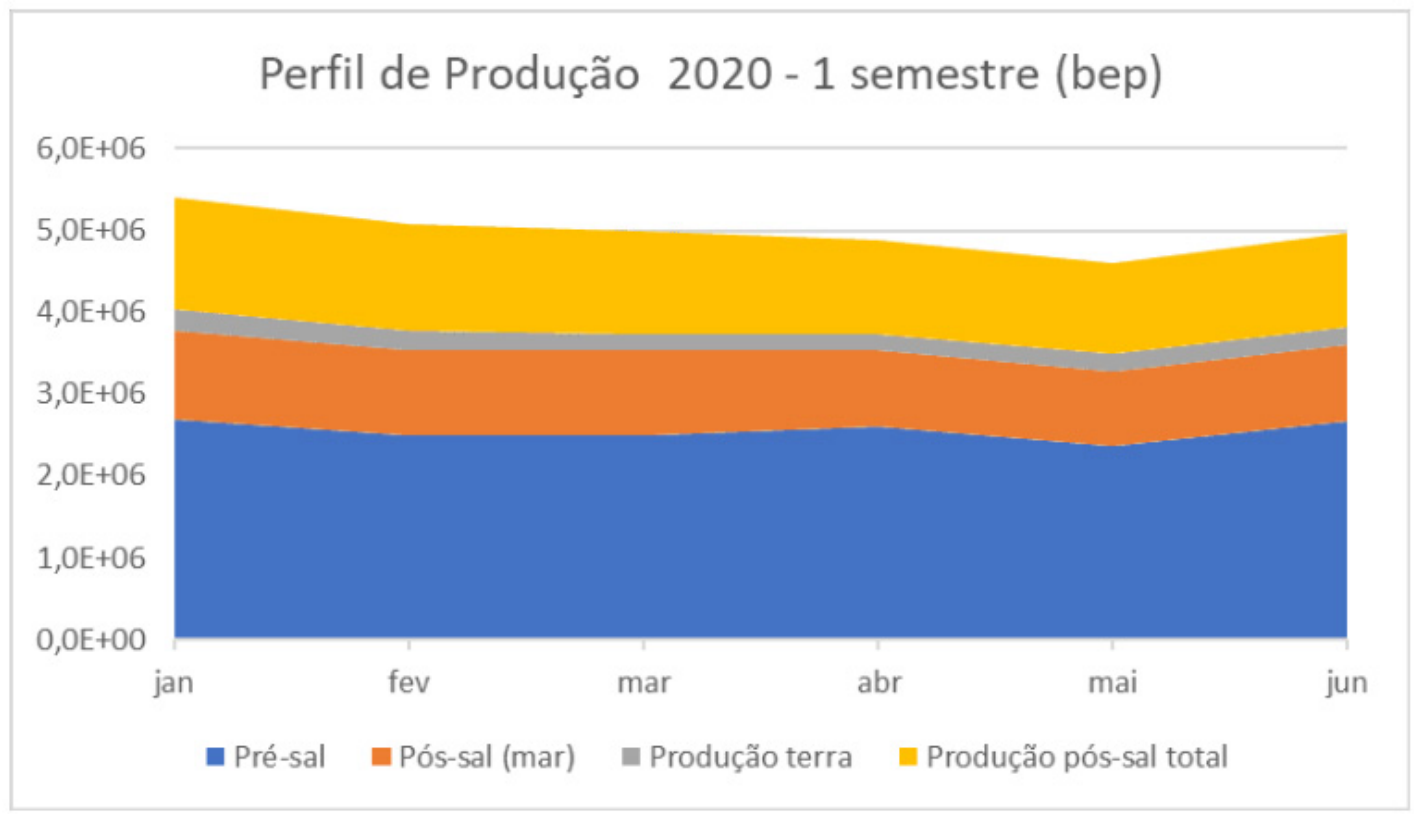

FONTE: Autor (2020), com base em dados da ANP

MESTR A D 0

PESQUISA OPERACIONAL E INTELIGÊNCIA COMPUTACIONAL LINHA DE PESQUISA EM SAÚDE

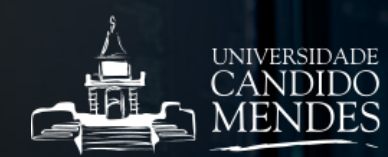


Embora a atuação cambial tenha sido favorável ao cálculo dos royalties, tendo em vista que a cotação internacional de petróleo e gás são indexadas em dólares, a combinação entre a queda de produção e de preço das commodities promoveu grande impacto na receita de royalties no primeiro semestre de 2020 (Fig. 5). Considerando que o cálculo de royalties é feito com base na produção anterior (2 meses), os royalties calculados no mês de junho de 2020 (produção de abril) registraram uma queda de 60,34\% frente à arrecadação de janeiro de
2020. A queda na receita de royalties no mês de abril foi de $8,83 \%$ quando comparada com a arrecadação de janeiro/2020, enquanto, em maio, foi observada queda de receita de $38,32 \%$ quando comparada ao início do semestre/2020. Os valores transferidos oriundos dos royalties no primeiro semestre de 2020 são apresentados na Tabela 1.

\section{Figura 5: Arrecadação de royalties na produção de petróleo no Brasil - primeiro semestre de 2020}

\section{Arrecadação de royalties (R\$)}

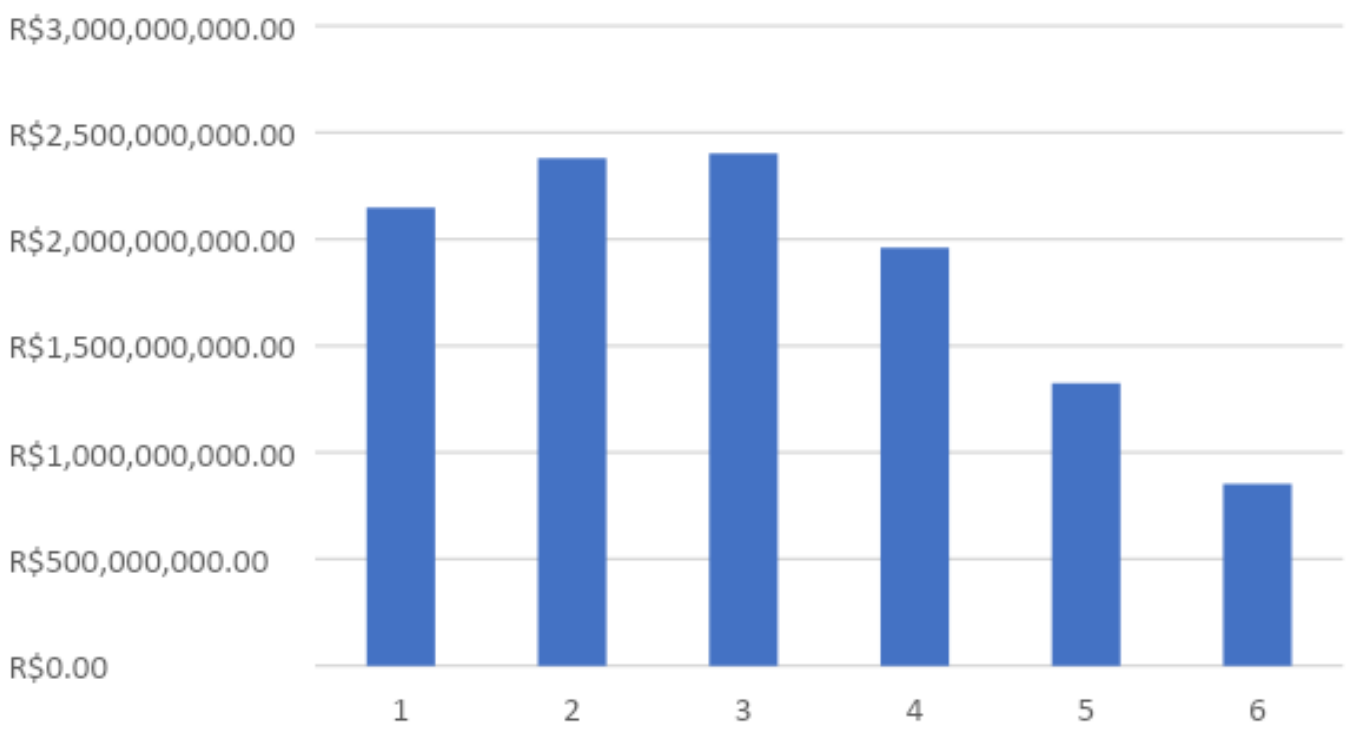

Figura 5: Arrecadação de royalties na produção de petróleo no Brasil - primeiro semestre de 2020

Figura 6: Arrecadação de participação especial na produção de petróleo no Brasil - primeiro semestre de 2020

\section{Arrecadação - Participação Especial (R\$)}

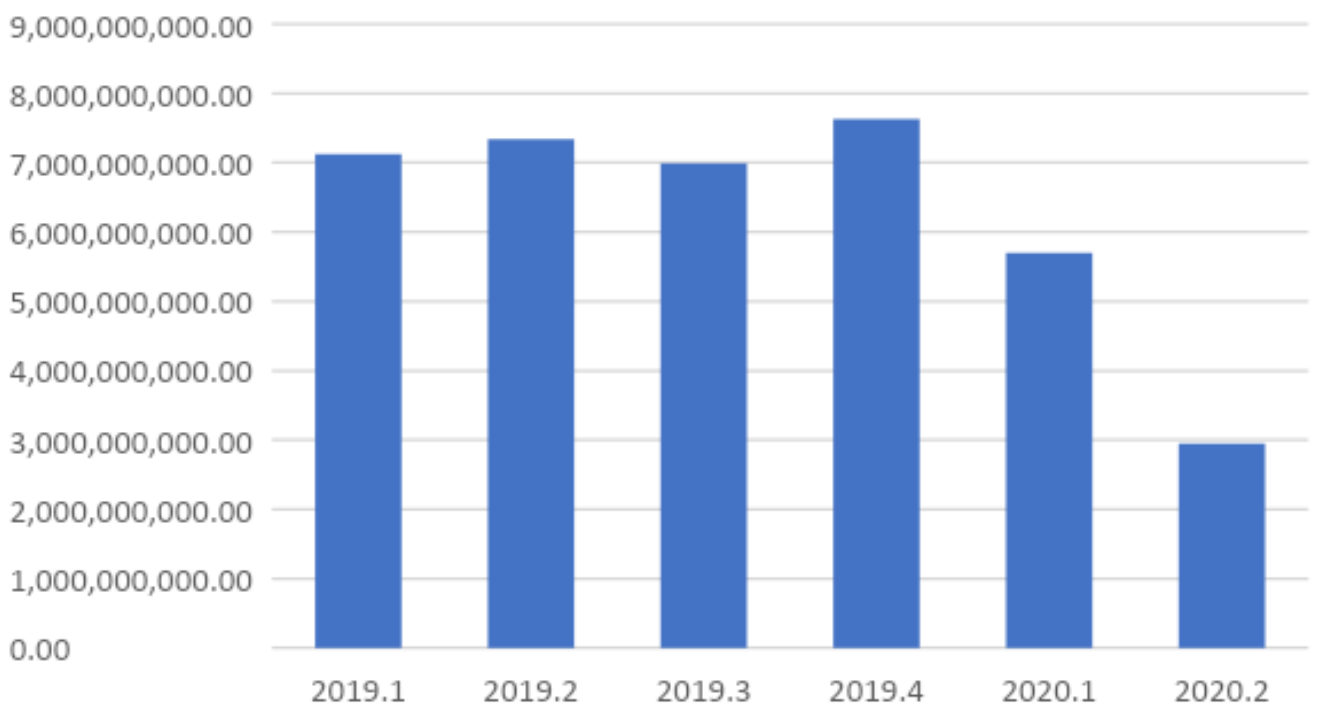

FONTE: Autor (2020), com base em dados da ANP 
Tabela 1: Distribuição de royalties na produção de petróleo no Brasil primeiro semestre de 2020

\begin{tabular}{|l|c|c|c|c|c|c|}
\hline BENEFICIARIOS & $\begin{array}{c}\text { jan./2020 } \\
\text { (R\$) }\end{array}$ & $\begin{array}{c}\text { fev./2020 } \\
\text { (RS) }\end{array}$ & $\begin{array}{c}\text { mar//2020 } \\
\text { (R\$) }\end{array}$ & $\begin{array}{c}\text { abr//2020 } \\
\text { (RS) }\end{array}$ & $\begin{array}{c}\text { maio/2020 } \\
\text { (RS) }\end{array}$ & $\begin{array}{c}\text { jun./2020 } \\
\text { (RS) }\end{array}$ \\
\hline ESTADOS & 595729046,2 & 660172636,5 & 665363685,6 & 542580383,3 & 366906176,6 & 237338381,5 \\
\hline MUNICIPIOS & 742699020,7 & 820942820,3 & 828766088 & 675733451,5 & 457612399,3 & 293618564 \\
\hline $\begin{array}{l}\text { FUNDO } \\
\text { ESPECIAL }\end{array}$ & 179996639,4 & 200538233,4 & 202604025,2 & 164941317,4 & 111569877,8 & 71492724,14 \\
\hline $\begin{array}{l}\text { COMANDO DA } \\
\text { MARINHA }\end{array}$ & 85511821,25 & 90607171,18 & 98156872,02 & 82672404,45 & 56355852,86 & 32354073,71 \\
\hline MCT & 72437380,49 & 74371218,72 & 79600024,7 & 66884764,95 & 45848327,05 & 26923924,61 \\
\hline FUNDO SOCIAL & 322826830,7 & 358611918,8 & 351187165,7 & 283266113,4 & 176307100 & 121721605 \\
\hline $\begin{array}{l}\text { EDUCAÇÄO E } \\
\text { SAÚDE - UNIÃO }\end{array}$ & 149804762,7 & 176023069,3 & 175986836,1 & 143177540,1 & 110939924,3 & 68646993,26 \\
\hline \multicolumn{1}{|c|}{ TOTAL } & 2149005501 & 2381267068 & 2401664697 & 1959255975 & 1325539658 & 852096266,2 \\
\hline
\end{tabular}

FONTE: Autor (2020), com base em dados da ANP

A redução de receita proveniente de participação especial no primeiro trimestre de 2020 atingiu o patamar de RS 5.695.851.905,01, indicando um recuo de 25,37\% em relação ao último trimestre de 2019. 0 cenário de arrecadação no segundo trimestre foi mais desafiador, com uma redução de 61,43\% em relação ao quarto trimestre de 2019, totalizando R\$2.943.803.590,26. A evolução de arrecadação de receitas provenientes de participação especial é apresentada na Figura 5.

\section{CONCLUSÕES}

A combinação de redução drástica da cotação internacional do petróleo aliada à queda de demanda durante o período de isolamento social no primeiro semestre de 2020 trouxeram um impacto significativo nas receitas geradas por royalties e participação especial provenientes da indústria do petróleo e gás, chegando a superar uma perda de $60 \%$ no período mais crítico de produção.

0 reflexo é sentido principalmente nos estados e municípios com grande produção, com perda significativa da receita. A recuperação de orçamento dependerá do equilíbrio entre oferta e demanda de petróleo no período de recuperação econômica, já sendo observado início de recuperação já no começo do segundo semestre, principalmente relacionada à cotação do petróleo de referência (Brent), sondando a cotação de US\$ 45 no final de julho de 2020, porém indicando ainda redução próxima de 32\% em relação ao início do ano de 2020. 


\section{Referências}

ANP. Resolução ANP n0 12, de 21 de fevereiro de 2014. Disponível em: http://legislacao.anp.gov.br///?path=legislacao-anp/resol-anp/2014/ fevereiro\&id=330\&sub=780. Acesso em: 23 ago. 2020.

ANP. Resolução ANP nº 40, de 14 de dezembro de 2019. Disponível em: http://legislacao.anp.gov.br/?path=legislacao-anp/resol-anp/2009/ dezembro\&item=ranp-40-2009\&export=pdf. Acesso em: 23 de ago. 2020

ANP. Resolução ANP n0 703, de 26 de setembro de 2017. Disponível em: http://legislacao.anp.gov.br/?path=legislacao-anp/resol-anp/2017/ setembro\&item=ranp-703-2017. Acesso em: 23 ago. 2020.

BADIANI, A. M.; VIEIRA,V. M.; ARAÚJO, P. S. R. Efeitos socioeconômicos e perspectivas da atividade de E\&P de Petróleo e Gás na Bacia do Recôncavo. Boletim Petróleo, Royalties e Região, Campos dos Goytacazes/RJ, Ano 16, n. 63, ago. 2019.

BRASIL. [Constituição (1988)]. Constituição da República Federativa do Brasil de 1988. Brasília, DF: Presidência da República, [2016]. Disponível em: http://www.planalto.gov.br/ccivil_03/Constituicao/ Constituiçao.htm. Acesso em: 23 ago. 2020.

BRASIL. Decreto n 2.705, de 3 de agosto de 1998. Disponível em: https://www2.camara.leg.br/legin/fed/decret/1998/decreto-2705-3-agosto-1998398055-norma-pe.html. Acesso em: 23 ago. 2020.

BRASIL. Decreto n 9.042, de 2 de maio de 2017. Disponível em: http://www.planalto.gov.br/ccivil_03/_Ato2015-2018/2017/Decreto/D9042.htm. Acesso em: 23 ago. 2020.

BRASIL. Lei nº 9.478, de 6 de agosto de 1997. Disponível em: http://www.planalto.gov.br/ccivil_03/leis/l9478.htm. Acesso em: 23 ago. 2020.

BRASIL. Lei n 7.790, de 28 de dezembro de 1989. Disponível em: http://www.planalto.gov.br/ccivil_03/LEIS/L7990.htm. Acesso em: 23 ago. 2020. 